\title{
Allylmercapturic acid as urinary biomarker of human exposure to allyl chloride
}

Leiden-Amsterdam Centre for Drug Research (LACDR), Division of Molecular Toxicology, Department of Pharmacochemistry, Free University, De Boelelaan 1083, 1081 HV Amsterdam, The Netherlands B M de Rooij J N M Commandeur N P E Vermeulen

Shell International Chemicals BV, Molecular Toxicology, Shell Research and Technology Centre, Amsterdam The Netherlands P J Boogaard N J van Sittert

Correspondence to: Professor NPE Vermeulen, Leiden-Amsterdam Centre for Drug Research (LACDR), Division of Molecular Toxicology, Department of

Pharmacochemistry, Free University, De Boelelaan 1083, 1081 HV Amsterdam, The Netherlands.

Ben M de Rooij, Pieter J Boogaard, Jan N M Commandeur, Nico J van Sittert, Nico P E Vermeulen

\begin{abstract}
Objective-To evaluate the use of urinary mercapturic acids as a biomarker of human exposure to allyl chloride (3chloropropene) (AC). During three regular shut down periods in a production factory for AC, both types of variables were measured in 136 workers involved in maintenance operations.
\end{abstract}

Methods-Potential airborne exposure to AC was measured by personal air monitoring in the breathing zone. In total 205 workshifts were evaluated. During 99 workshifts no respiratory protection equipment was used. Mercapturic acid metabolites were measured in urinary extracts by gas chromatography-mass spectrometry (GC-MS).

Results-During 86 work shifts when no respiratory protection was used the air concentrations of AC were below the Dutch eight hour time weighted average (8h-TWA) occupational exposure limit (OEL) of AC $\left(3 \mathrm{mg} / \mathrm{m}^{3}\right)$, whereas in 13 workshifts the potential exposure, as measured by personal air monitoring, exceeded the OEL $\left(3.3\right.$ to $\left.17 \mathrm{mg} / \mathrm{m}^{3}\right)$. With the aid of GC-MS, 3-hydroxypropylmercapturic acid (HPMA) was identified as a minor and allylmercapturic acid (ALMA) as a major metabolite of AC in urine samples from the maintenance workers exposed to AC. The concentrations of ALMA excreted were in a range from $<25 \mu \mathrm{g} / \mathrm{l}$ (detection limit) to 3550 $\mu \mathrm{g} / \mathrm{l}$. The increases in urinary ALMA concentrations during the workshifts correlated well with the 8h-TWA air concentrations of $\mathrm{AC}(r=0.816, P=0.0001$, $n=39$ ). Based on this correlation, for $A C$ a biological exposure index (BEI) of $352 \mu \mathrm{g}$ ALMA/g creatinine during an eight hour workshift is proposed. In some urine samples unexpectedly high concentrations of ALMA were found. Some of these could definitely be attributed to dermal exposure to AC. In other cases garlic consumption was identified as a confounding factor.

Conclusion-The mercapturic acid ALMA was identified in urine of workers occupationally exposed to airborne AC and the increase in ALMA concentrations in urine during a workshift correlated well with the 8h-TWA exposure to AC. Garlic consumption, but not smoking, is a potential confounding factor for this biomarker of human exposure to $A C$.

\section{(Occup Environ Med 1997;54:653-661)}

Keywords: allyl chloride; mercapturic acids; biological monitoring

Allyl chloride (3-chloropropene) (AC, CAS number 107-05-01) is a colourless liquid with a pungent odour. Allyl chloride is often used as an intermediate in the synthesis of epichlorohydrin, a precursor used in the production of epoxy resins. ${ }^{1}$ In most countries, the eight hour time weighed average occupational exposure limit (8h-TWA OEL) for AC is $1 \mathrm{ppm}$ (3 $\left.\mathrm{mg} / \mathrm{m}^{3}\right)^{2}$

In humans exposed to high concentrations of AC, several toxic effects have been found. In workers in a sodium allyl sulphonate production unit, exposed to extremely high concentrations $\mathrm{AC}$ (up to $6650 \mathrm{mg} / \mathrm{m}^{3}$ air), peripheral neurotoxic effects were found. ${ }^{3}$ Reversible liver damage determined by increased serum enzyme activities ${ }^{4}$ was found in workers exposed to $\mathrm{AC}$ concentrations up to $350 \mathrm{mg} / \mathrm{m}^{3}$ air. In more recent studies in an AC production plant with airborne exposures up to $4.8 \mathrm{mg} \mathrm{AC} / \mathrm{m}^{3}$ air (8h-TWA); however, no impaired liver or kidney functions were found. ${ }^{5}$

In rodents several subchronic effects of $\mathrm{AC}$ have been found. ${ }^{6} 7$ Guinea pigs and rats, during one month exposed to air concentrations of $25 \mathrm{mg} \mathrm{AC} / \mathrm{m}^{3}$, showed histologically observable adverse effects on liver and kidneys. ${ }^{7}$ After high semichronic $\mathrm{AC}$ exposures $\left(200 \mathrm{mg} \mathrm{AC} / \mathrm{m}^{3}\right.$ for three months) of rabbits and cats, neurotoxic effects were identified from changes in electromyograms and these effects were accompanied by degeneration of myelin sheaths in peripheral nerves and by impaired motor functions. These effects were not found in rabbits and rats at lower exposures-for example, $17 \mathrm{mg} \mathrm{AC} / \mathrm{m}^{3}$ for five months. ${ }^{6}$ Allyl chloride has been shown to be mutagenic in various Salmonella typhimurium strains. ${ }^{8-10}$ In mice tumours were only seen at the site of application of AC when combined with a tumour promoter ${ }^{11}$ or when mice were treated intraperitoneally with maximal tolerated doses of $\mathrm{AC}^{12}$ There are no indications that $\mathrm{AC}$ is a human carcinogen. ${ }^{1}$

The biotransformation of $\mathrm{AC}$ has been investigated almost exclusively in rats. ${ }^{13-15}$ 
Table $1{ }^{1} H$-NMR, electron impact (EI) mass spectrometric (MS), and gas chromatographic (GC) retention time data of mercapturic acids of interest in this study

\begin{tabular}{|c|c|c|}
\hline Compound & ${ }^{1} H-N M R(\delta \text { in } p p m)^{*}$ & $M S(E I)$; derivative, retention time ( $m / z$, fragment, intensity) \\
\hline ALMA & $\begin{array}{l}2.04\left[\mathrm{~s} 3 \mathrm{H}-\mathrm{COCH}_{3}\right] \\
4.38-4.48\left[\mathrm{~m} 1 \mathrm{H}-\mathrm{SCH}_{2} \mathrm{CH}\right] \\
2.78-3.05\left[\mathrm{~m}_{2} \mathrm{H}-\mathrm{SCH}_{2} \mathrm{CH}\right] \\
3.20\left[\mathrm{~d} 2 \mathrm{H} \mathrm{CH} 2=\mathrm{CHCH}_{2} \mathrm{~S}-\right] \\
5.70-5.93\left[\mathrm{~m} 1 \mathrm{H} \mathrm{CH} \mathrm{CH}_{2}=\mathrm{CH}_{\mathrm{H}} \mathrm{CH}_{2} \mathrm{~S}-\right] \\
5.11 \text { and } 5.20\left[\mathrm{~s}+\mathrm{d} 2 \mathrm{H} \mathrm{C} \underline{\mathrm{H}}_{2}=\mathrm{CHCH}_{2} \mathrm{~S}-\right]\end{array}$ & $\begin{array}{l}\text { Methylester, } 10.4 \mathrm{~min} \\
217\left([\mathrm{M}]^{+\bullet}, 10.2 \%\right) \\
176\left(\left[\mathrm{M}-\mathrm{CH}_{2}=\mathrm{CHCH}_{2}\right]^{+}, 28 \%\right) \\
158\left(\left[\mathrm{M}-\mathrm{COOCH}_{3}\right]^{+} \text {or }\left[\mathrm{M}-\mathrm{NH}_{2} \mathrm{COCH}_{3}\right]^{+\bullet}, 100 \%\right) \\
144\left(\left[\mathrm{M}-\mathrm{CH}_{2}=\mathrm{CHCH}_{2} \mathrm{~S}\right]^{+}, 24 \%\right) \\
117\left(\left[176-\mathrm{NH}_{2} \mathrm{COCH}_{3}\right]^{+} \text {or }\left[\mathrm{M}-\mathrm{COOCH}_{3}\right]^{+\bullet}, 74 \%\right)\end{array}$ \\
\hline $\mathrm{D}_{3}$-ALMA & $\begin{array}{l}4.27-4.38\left[\mathrm{~m} 1 \mathrm{H}-\mathrm{SCH}_{2} \mathrm{CH}\right] \\
2.70-3.00\left[\mathrm{~m}_{2} \mathrm{H}-\mathrm{SCH}_{2} \mathrm{CH}\right] \\
3.15\left[\mathrm{~d} 2 \mathrm{H} \mathrm{CH} \mathrm{CHCH}_{2}=\mathrm{CHC}_{2} \mathrm{~S}\right] \\
5.70-5.91\left[\mathrm{~m} 1 \mathrm{H} \mathrm{CH}_{2}=\mathrm{CH}_{\mathrm{H}} \mathrm{CH}-\right] \\
5.12 \text { and } 5.20\left[\mathrm{~s}+\mathrm{d} 2 \mathrm{H} \mathrm{C} \underline{\mathrm{H}}_{2}=\mathrm{CHCH}_{2} \mathrm{~S}-\right]\end{array}$ & $\begin{array}{l}\text { Methylester, } 10.4 \mathrm{~min} \\
220\left([\mathrm{M}]^{+\bullet}, 6 \%\right) \\
179\left(\left[\mathrm{M}-\mathrm{CH}_{2}=\mathrm{CHCH}_{2}\right]^{+}, 26 \%\right) \\
158\left(\left[\mathrm{M}-\mathrm{COOCH}_{3}\right]^{+} \text {or }\left[\mathrm{M}-\mathrm{NH}_{2} \mathrm{COCD}_{3}\right]^{+\bullet}, 100 \%\right) \\
147\left(\left[\mathrm{M}-\mathrm{CH}_{2}=\mathrm{CHCH}_{2} \mathrm{~S}\right]^{+}, 27 \%\right)\end{array}$ \\
\hline HPMA & $\begin{array}{l}2.02\left[\mathrm{~s} 3 \mathrm{H}-\mathrm{COCH}_{3}\right] \\
4.26-4.36\left[\mathrm{~m} 1 \mathrm{H}-\mathrm{SCH}_{2} \mathrm{CH}\right] \\
2.72-3.06\left[\mathrm{~m} 2 \mathrm{H}-\mathrm{SCH}_{2} \mathrm{CH}\right] \\
2.54-2.66\left[\mathrm{t} 2 \mathrm{H} \mathrm{HOCH} \mathrm{CH}_{2} \mathrm{CH}_{2} \mathrm{~S}-\right] \\
1.68-1.89\left[\mathrm{~m} 2 \mathrm{H} \mathrm{HOCH} \mathrm{HOH}_{2} \mathrm{CH}_{2} \mathrm{~S}-\right] \\
3.49-3.71\left[\mathrm{t} 2 \mathrm{H} \mathrm{HOCH} \mathrm{CH}_{2} \mathrm{CH}_{2} \mathrm{~S}-\right]\end{array}$ & $\begin{array}{l}\text { Methylester, } 14.8 \mathrm{~min} \\
235\left([\mathrm{M}]^{+\bullet}, 1.5 \%\right) \\
176\left(\left[\mathrm{M}-\mathrm{CH}_{2}(\mathrm{OH}) \mathrm{CH}_{2} \mathrm{CH}_{2}\right]^{+}, 50 \%\right) \\
158\left(\left[\mathrm{M}-\mathrm{H}_{2} \mathrm{O}-\mathrm{COOCH}\right]_{3} \text { or }\left[\mathrm{M}-\mathrm{H}_{2} \mathrm{O}-\mathrm{NH}_{2} \mathrm{COCH}_{3}\right]^{+\bullet}, 39 \%\right) \\
144,\left(\left[\mathrm{M}-\mathrm{CH}_{2}(\mathrm{OH}) \mathrm{CH}_{2} \mathrm{CH}_{2} \mathrm{~S}\right]^{+}, 13 \%\right)\end{array}$ \\
\hline$D_{5}$-PMA & $\begin{array}{l}1.91\left[\mathrm{~s} 3 \mathrm{H}-\mathrm{COCH} \underline{H}_{3}\right] \\
4.79-4.86\left[\mathrm{~m} 1 \mathrm{H}-\mathrm{C}_{6} \mathrm{D}_{5} \mathrm{SCH}_{2} \mathrm{CH}\right] \\
3.34-3.61\left[\mathrm{~m} 2 \mathrm{H}-\mathrm{C}_{6} \mathrm{D}_{5} \mathrm{SCH}_{2} \mathrm{CH}\right]\end{array}$ & $\begin{array}{l}\text { Methylester, } 17.2 \mathrm{~min} \\
258\left([\mathrm{M}]^{+\bullet}, 15 \%\right) \\
199\left(\left[\mathrm{M}-\mathrm{COOCH}_{3}\right]^{+} \text {or }\left[\mathrm{M}-\mathrm{NH}_{2} \mathrm{COCH}_{3}\right]^{+\bullet}, 100 \%\right) \\
140\left(\left[\mathrm{M}-\mathrm{COOCH}_{3}-\mathrm{NH}_{2} \mathrm{COCH}_{3}\right]^{+}, 57 \%\right) \\
128\left(\left[\mathrm{C}_{6} \mathrm{D}_{5} \mathrm{SCH}_{2}\right]^{+}, 40 \%\right) \\
114\left(\left[\mathrm{C}_{6} \mathrm{D}_{5} \mathrm{~S}\right]^{+}, 15 \%\right)\end{array}$ \\
\hline
\end{tabular}

* Relative to tetramethylsilane, $\mathrm{NMR}$ in $\mathrm{D}_{2} \mathrm{O} / \mathrm{NaCO}_{3} . \mathrm{s}=$ Singlet; $\mathrm{d}=$ doublet; $\mathrm{m}=$ multiplet.

Two urinary mercapturic acid metabolites were identified in rats. ${ }^{14} 15$ 3-Hydroxypropylmercapturic acid (HPMA) was reported to be a major and allylmercapturic acid (ALMA) a minor urinary metabolite of $A C$ in rats. However, recently we investigated the urinary metabolite profile of AC in rats ${ }^{16}$ after intraperitoneal administration. At doses between 5 and $45 \mathrm{mg} / \mathrm{kg}$ about $30 \%$ of the AC dose was excreted in urine as ALMA. Also, minor amounts of HPMA, 3-chloro-2-hydroxypropylmercapturic acid (CHPMA), and $\alpha$-chlorohydrin $(\alpha-\mathrm{CH})$ were measured, for < $3.0 \%, 0.20 \%$, and $0.13 \%$ of the AC dose, respectively. The urinary excretion of CHPMA and $\alpha-\mathrm{CH}$ suggests the formation of epichlorohydrin from AC in the rat. The oxidation of AC to $\mathrm{ECH}$ has been suggested as playing a part in the tumorigenic activity of $A C$ in mice. ${ }^{11}$ The urinary excretion of ALMA has also been shown to be related to garlic consumption ${ }^{17}$ whereas the urinary excretion of HPMA was also found in rats treated with acrolein, ${ }^{13}{ }^{15}$ a compound found in cigarette smoke. ${ }^{1819}$

Mercapturic acids have often been used as biomarkers of human exposure to electrophilic chemicals. ${ }^{20} 21$ The mercapturic acid pathway is generally considered to be a detoxification pathway. ${ }^{22}$ However, in some cases this metabolic pathway can lead to toxicity as well. ${ }^{23}{ }^{24}$ Recent examples of the use of mercapturic acids as a biomarker of human exposure are Zand E-3-chloropropenylmercapturic acid as biomarkers of exposure to $\mathrm{Z}$ - and E-1,3-dichloropropene ${ }^{25}$ and phenylmercapturic acid as biomarker of exposure to benzene. ${ }^{26} 27$

The present study was undertaken to evaluate the utility of urinary mercapturic acids as biomarkers of human AC exposure. The study was undertaken in an organochlorine production plant, in which AC is produced by chlorination of propene and subsequently used in the synthesis of epichlorohydrin. The biomonitoring sessions were performed in maintenance workers during three annual maintenance shut down periods in which AC production was stopped, installations were cleaned and maintenance was performed. During these periods the potential exposure to AC was determined in the breathing zone by personal air monitoring.

\section{Materials and methods}

CHEMICALS

Allyl bromide (>99\%) was obtained from Aldrich (Beerse, Belgium), benzylmercapturic acid $(>99 \%)$ and $\mathrm{N}$-acetyl-L-cysteine $(>96 \%)$ were obtained from Janssen Chimica (Geel, Belgium), and creatinine ( $>98 \%$ ) from $\mathrm{JT}$ Baker (Deventer, The Netherlands). All chemicals used were of the highest purity available.

SYNTHESIS

Synthesis of allylmercapturic acid (ALMA)

ALMA was synthesised as described previously ${ }^{17}$ with slight modifications. In short: allyl bromide $(1.2 \mathrm{~g}, 10 \mathrm{mmol})$ was added to a mixture of $1.6 \mathrm{~g}(10 \mathrm{mmol}) \mathrm{N}$-acetyl-Lcysteine in $10 \mathrm{ml}$ methanol and $0.24 \mathrm{~g}(20$ mmol) sodium. The mixture was allowed to stand at room temperature for four hours and was subsequently neutralised with $2 \mathrm{~N} \mathrm{HCl}$. After rotary evaporation of methanol, the residue was dissolved in $10 \mathrm{ml} 2 \mathrm{~N} \mathrm{HCl}$ and extracted with two $30 \mathrm{ml}$ volumes of ethyl acetate. After rotary evaporation of the organic solvent the product appeared as a white powder and was recrystallised from hot acetone. The overall yield was about $80 \%$. The identification data on ALMA, and the other synthetic products (described later), were obtained with ${ }^{1} \mathrm{H}-\mathrm{NMR}$ and gas chromatography-mass spectrometry (GC-MS) (table 1).

\section{Synthesis of 3-hydroxypropylmercapturic acid} (HPMA)

HPMA was synthesised and identified as described before. ${ }^{131516}$ 
Synthesis of trideuteroacetyl-allylmercapturic acid $\left(D_{3}-A L M A\right)$

$\mathrm{D}_{3}$-ALMA was synthesised by addition of hexadeuteroacetic anhydride in an aqueous solution of S-(allyl)-L-cysteine, as described before. ${ }^{28}$ The S-(allyl)-L-cysteine used in this reaction was synthesised as described elsewhere. ${ }^{14}$

Synthesis of pentadeutero-phenylmercapturic acid $\left(D_{5}-P M A\right)$

$\mathrm{D}_{5}$-PMA was synthesised and identified as described before. ${ }^{27}$

\section{HUMAN STUDY AND ANALYSIS}

Study design and collection of urine samples

This study was performed during so called shut down periods in a production factory for AC. In this factory AC is produced in a completely closed system with little chance for human exposure. During a shut down period the installation is rinsed and subsequently opened for maintenance and inspection operations. Before the start of the experiments the volunteers participating in this biomonitoring study were informed about the aim, the procedure, and the potential outcome of the study. Male workers ( $n=136$, age: $20-55$ years) involved in maintenance and inspection operations during shut down periods in three consecutive years $(1991,1992$, and 1993) participated in the study. Information on occupational history, demographic characteristics, and various lifestyle factors was obtained by a self administered questionnaire and from plant records. In 1992 and 1993 information was also gathered about garlic consumption. None of the workers was involved in two or three consecutive years. Before inspection and maintenance operations began, the production installations were successively rinsed with alkali and solvent, and finally steam cleaned until no organochlorine compounds could be detected in the effluent. Depending on the job, various types of personal protection equipment were used according to instructions of an occupational hygienist. During all tasks potential exposures to airborne AC were assessed by personal air monitoring (PAM). Urinary spot samples were collected at the beginning and the end of each shift. The samples were immediately acidified to $\mathrm{pH} \mathrm{1-2}$ by addition of $6 \mathrm{M}$ $\mathrm{HCl}$ and stored at $4^{\circ} \mathrm{C}$ until analysis. ALMA was stable for up to one month under these conditions.

\section{Personal air monitoring}

Potential exposure to airborne AC was assessed throughout the workshifts by personal air monitoring with $3 \mathrm{M}$ organic vapour monitors (type 3500), which were attached on the right lapel by the occupational hygienist. If any respiratory protection equipment was used the badges were worn on the outside. Immediately after sampling the badges were capped and stored frozen at $-20^{\circ} \mathrm{C}$ until analysis. Within one week the absorbed amounts of AC were desorbed with $1.5 \mathrm{ml}$ carbon disulphide with continuous shaking for 30 minutes. The mean (SD) recovery of $\mathrm{AC}$ according to this procedure was $91 \%(3 \%)$; all values were corrected for AC recovery. Aliquots of $1 \mu \mathrm{l}$ of the carbon disulphide solution were injected (split injection; split flow $35 \mathrm{ml} / \mathrm{min}$ ) on a $60 \mathrm{~m}$ $\times 0.32 \mathrm{~mm}$ (internal diameter) DB-1 column (Durabond, J and W, Folsom, California, USA) with a film thickness of $1 \mu \mathrm{m}$ and helium as carrier gas (50 kPa prepressure; column flow about $1.6 \mathrm{ml} / \mathrm{min}$ ) on a HP 5890 series 2 gas chromatograph equipped with flame ionisation detection. Injector and detector temperature were $250^{\circ} \mathrm{C}$. The oven was programmed from $40^{\circ} \mathrm{C}$ (seven minutes) to $250^{\circ} \mathrm{C}$ at a rate of $10 \%$ minute. The final temperature was kept for five minutes. The calibration curve was linear from the detection limit of the method (0.1 $\left.\mathrm{mg} / \mathrm{m}^{3}, \mathrm{~S} / \mathrm{N}=10\right)$ up to at least $20 \mathrm{mg} / \mathrm{m}^{3}(8 \mathrm{~h}-$ TWA).

\section{Determination of urinary creatinine concentrations}

Creatinine concentrations were determined on a Cobas Mira autoanalyser by the Jaffé method. $^{29}$

\section{Isolation and determination of $A L M A$ in urine}

To $1 \mathrm{ml}$ aliquots of the acidified urine samples $30.0 \mu \mathrm{l}$ of a solution of $20.0 \mu \mathrm{M}$ BEMA (1991, 1992) or $D_{5}$-PMA (1993) in $0.06 \mathrm{M} \mathrm{HCl}$ was added as the internal standard. The urinary mixture was extracted with $4 \mathrm{ml}$ ethyl acetate by an automated shaker during three minutes. The organic phase was separated by centrifugation (three minutes, $800 \mathrm{~g}$ ), transferred into a test tube, and evaporated to dryness by a gentle stream of nitrogen on a waterbath maintained at $45^{\circ} \mathrm{C}$. The residue was methylated at room temperature with $2.0 \mathrm{ml}$ of a $1.25 \mathrm{M}$ solution of $\mathrm{HCl}$ gas in methanol as described previously. ${ }^{26}$ After 30 minutes, the excess methanolic $\mathrm{HCl}$ was evaporated by a gentle stream of nitrogen on a waterbath controlled thermostatically at $45^{\circ} \mathrm{C}$ and the residue was dissolved in $1.0 \mathrm{ml}$ dichloromethane. This solution was analysed by GC-MS with an HP 5890 series 2 GC (Hewlett Packard, Palo Alto, USA) equipped with a 5971A mass selective detector (ion source temperature $180^{\circ} \mathrm{C}$, electron energy $70 \mathrm{eV}$ ) and a 7673 autosampler. Splitless injections of $1 \mu \mathrm{l}$ were made (injector and inlet line temperature $250^{\circ} \mathrm{C}$ ) and chromatographed on a $60 \mathrm{~m} \times 0.22 \mathrm{~mm}$ (internal diameter) fused silica DB-1 column (film thickness $0.1 \mu \mathrm{m}$ ) (Durabond) with helium as carrier gas at $170 \mathrm{kPa}$ (about $1 \mathrm{ml} / \mathrm{min}$ ) and the following temperature programme: $35^{\circ} \mathrm{C}$ for one minute and then at $10^{\circ} /$ minute to $300^{\circ} \mathrm{C}$, which was maintained for 7.5 minutes. Full scanning $(\mathrm{m} / \mathrm{z} 50-550,1.1 \mathrm{scan} / \mathrm{s})$ was used for identification purposes and for the selection of signals appropriate for selected ion monitoring (SIM) experiments. For the measurement of ALMA the signals at $\mathrm{m} / \mathrm{z} 158$ and 217 (ions of ALMA methyl ester) and either 176 and 208 (ions of BEMA methyl ester) or 199 and 258 (ions of $\mathrm{D}_{5}$-PMA methyl ester) were monitored. Calibration curves were constructed from control urine samples, spiked with synthetic ALMA. 
Table 2 Ambient air concentrations of allyl chloride (AC) during shut down periods in an AC production facility

\begin{tabular}{|c|c|c|c|c|c|c|c|c|c|}
\hline \multirow[b]{3}{*}{ Year } & \multirow[b]{3}{*}{$n^{*}$} & \multicolumn{8}{|c|}{ Personal air monitoring of ambient concentrations of $A C t$} \\
\hline & & \multicolumn{4}{|c|}{ Without respiratory protection } & \multicolumn{4}{|c|}{ With respiratory protection $\neq$} \\
\hline & & $n$ & Range & Mean $(S D)$ & Median & $n$ & Range & Mean $(S D)$ & Median \\
\hline $\begin{array}{l}1991 \\
1992 \\
1993\end{array}$ & $\begin{array}{l}46(39) \\
45(34) \$ \\
114(63)\end{array}$ & $\begin{array}{l}33(26) \\
10(9) \\
56(35)\end{array}$ & $\begin{array}{l}<0.1-17 \\
0.2-12 \\
<0.1-14\end{array}$ & $\begin{array}{l}1.5(3.6) \\
3.3(4.6) \\
1.5(3.1)\end{array}$ & $\begin{array}{l}0.3 \\
1.1 \\
0.1\end{array}$ & $\begin{array}{l}13(13) \\
16(13) \\
58(43)\end{array}$ & $\begin{array}{l}<0.1-23 \\
0.2-195 \\
<0.1-11\end{array}$ & $\begin{array}{l}2.2(5.6) \\
18.3(48.3) \\
1.7(3.1)\end{array}$ & $\begin{array}{l}0.3 \\
2.7 \\
0.16\end{array}$ \\
\hline
\end{tabular}

$\star^{\mathrm{n}}=$ number of air samples determined (number of people involved); $†$ the detection limit of the method was $0.1 \mathrm{mg} \mathrm{AC} / \mathrm{m} 3$ (8h-TWA); $\ddagger$ ambient concentrations of $\mathrm{AC}$ were determined outside of the respiratory protection equipment; $₫$ for 19 air samples no report was made on the use of respiratory protection.

\section{Isolation and determination of ALMA and} HPMA in urine

ALMA and HPMA were isolated from acidified urine samples as described elsewhere. ${ }^{16}$ In short: to an aliquot of $1 \mathrm{ml}$ urine $50 \mu \mathrm{l}$ of a solution of $50 \mu M D_{3}$-ALMA was added as the internal standard and the $\mathrm{pH}$ was adjusted to $1.2-1.7$ by addition of $0.1-0.2 \mathrm{ml} 2 \mathrm{~N} \mathrm{HCl}$. Organic components were extracted with solid phase extraction columns (RP18, Baker, Philipsburg, USA), which were pretreated with $3 \mathrm{ml}$ methanol and $3 \mathrm{ml}$ water (brought to $\mathrm{pH}$ 2 with $\mathrm{HCl}$ ). The columns were dried by centrifugation ( $400 \mathrm{~g}$ for 10 minutes) and the organic components were subsequently eluted by $3 \mathrm{ml}$ methanol. The methanol fraction was evaporated to dryness and the residue methylated as already described. After evaporation of methanol, the residue was dissolved in $0.5 \mathrm{ml}$ ethyl acetate and $1 \mu \mathrm{l}$ was used for GC-MS analysis, which was performed on an HP 5890 gas chromatograph equipped with a 5970 MSD (electron impact ionisation, electron energy $=70 \mathrm{eV}$ ), a split/splitless injector (used in splitless mode at injection). The oven was programmed from $50^{\circ} \mathrm{C}$ (one minute) to $250^{\circ} \mathrm{C}$ at a rate of $20^{\circ} \mathrm{C} /$ minute. A Cp Sil $5 \mathrm{CB}$ column (length $50 \mathrm{~m}$, internal diameter 0.25 $\mathrm{mm}$, stationary phase thickness $0.2 \mu \mathrm{m}$, Chrompack, Bergen op Zoom, The Netherlands) was used. Helium was used as carrier gas (2.5 $\mathrm{ml} / \mathrm{min})$. The GC-MS was operated in selected ion monitoring (SIM) mode. Specific ions were measured for ALMA, $D_{3}$-ALMA, and HPMA (table 1).

\section{Chemical ionisation $G C-M S$}

To confirm the identity of ALMA, a Finnigan MAT 90 GC-MS system was used. A Cp Sil 19 CB column ( $50 \mathrm{~m} \mathrm{x} 0.25 \mathrm{~mm}$, film thickness $0.2 \mu \mathrm{m}$ ) was used. The temperature of the injection port and transfer line were $250^{\circ} \mathrm{C}$. The oven was programmed from $70^{\circ} \mathrm{C}(0.5$ minutes) to $250^{\circ} \mathrm{C}$ at a rate of $20^{\circ} \mathrm{C} /$ minute The final temperature was kept constant for 15 minutes. Helium was used as carrier gas, with a column head pressure of $130 \mathrm{kPa}$, resulting in a column flow of about $2 \mathrm{ml} / \mathrm{min}$. Positive chemical ionisation was performed with methanol as reagent gas (indicated source pressure $4 \times 10^{-4}$ torr, source temperature $110^{\circ} \mathrm{C}$, ionisation current $0.20 \mathrm{~mA}$, and electron energy of $150 \mathrm{eV}$ ), signals were scanned between $\mathrm{m} / \mathrm{z} 190$ and 280 with a scan speed of 2.3 scans/s. For the synthetic products of ALMA and HPMA quasimolecular ions, $[\mathrm{M}+\mathrm{H}]^{+}$, were seen at $\mathrm{m} / \mathrm{z} 218$ and 236, respectively.

\section{CALCULATIONS}

From the amounts of AC absorbed on the organic vapour monitors the 8h-TWA air concentrations of AC were calculated for the various workshifts. By plotting the urinary ALMA concentration, adjusted for creatinine excretion, and the 8h-TWA air concentrations of AC versus time, urinary excretion-time profiles were constructed for every worker. From the values before and after the shift of all workers involved, the increase in ALMA concentration during the shift was calculated and plotted against the average respiratory air concentrations of $\mathrm{AC}$ to obtain the correlation between air concentration and urinary ALMA excretion.

\section{Results}

PERSONAL AIR MONITORING OF POTENTIAL EXPOSURE TO AC

In total 205 workshifts were evaluated (table 2). During 99 workshifts no respiratory protection equipment was used. In 86 of these shifts the air concentrations of AC were below the Dutch 8h-TWA occupational exposure limit (OEL) of $3 \mathrm{mg} \mathrm{AC} / \mathrm{m}^{3},{ }^{2}$ but in 13 workshifts the potential exposure to AC exceeded the Dutch 8h-TWA OEL (range 3.3 to $17 \mathrm{mg}$ $\left.\mathrm{AC} / \mathrm{m}^{3}\right)$. The median air concentrations of $\mathrm{AC}$ for workers not using personal respiratory protection equipment were found between 0.16 and $2.7 \mathrm{mg} \mathrm{AC} / \mathrm{m}^{3}$ (table 2). In two cases (1992) high air concentrations of AC were measured outside the respiratory equipment.

IDENTIFICATION OF URINARY METABOLITES OF AC ALMA was identified in ethyl acetate extracts of acidified urine samples of maintenance workers with the aid of chemical ionisation and electron impact GC-MS. With chemical ionisation GC-MS, the urinary excretion of ALMA was identified by a quasimolecular ion at $\mathrm{m} / \mathrm{z}$ 218 (data not shown), and with electron impact GC-MS by selective ion chromatograms of the ions at $\mathrm{m} / \mathrm{z} 144,158$, and 176 from ALMA and at $\mathrm{m} / \mathrm{z} 147,158$, and 179 from the trideuteroacetyl-analogue of ALMA (fig 1). HPMA was isolated from acidified urine samples by solid phase extraction. Attempts to identify the excretion of HPMA with chemical ionisation GC-MS were unsuccessful. However, the excretion of HPMA was identified in a few urine samples, by SIMGC-MS (electron impact) of the ions at $\mathrm{m} / \mathrm{z}$ 144, 158, and 176 (data not shown). The HPMA excretion was not always related to exposure to AC. Due to the relatively low response of HPMA on GC-MS under electron 

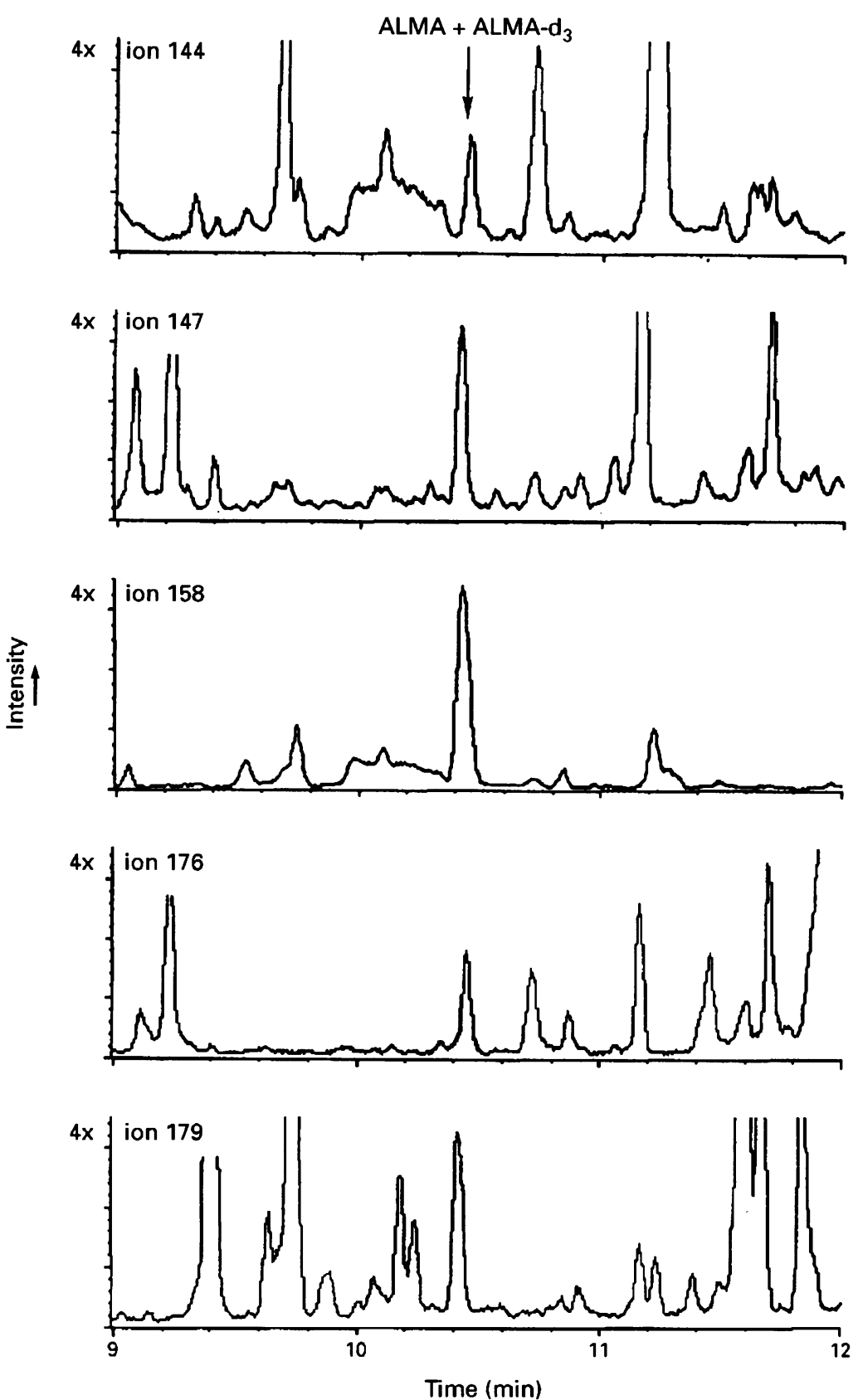

Figure 1 Identification of ALMA in a urine sample collected from worker $C$ (1993), occupationally exposed to ambient $1.4 \mathrm{mg} / \mathrm{m}^{3}$ ( $\left.8 \mathrm{~h}-T W A\right) A C$. Worker $C$ did not use personal respiratory protection equipment during this workshift. The urinary excretion of $A L M A$ was confirmed by selected ion monitoring GC-MS (electron impact) of the ions at $\mathrm{m} / \mathrm{z} 144,158$, and 176 from $A L M A$ and the ions at $\mathrm{m} / \mathrm{z} 147,158$, and 179 from the trideuteroacetyl-analogue of $A L M A$.

impact conditions and due to poor reproducibility, we were not able to measure the small amounts of HPMA excreted in urine.

MEASUREMENT OF URINARY ALMA EXCRETION The recovery of ALMA upon extraction with ethyl acetate from acidified urine samples was invariably $\geqslant 90 \%$. Calibration curves constructed with spiked urine samples and determined with SIM-GC-MS (electron impact) were linear $(r>0.98)$ from 25 to $5000 \mu \mathrm{g} / 1$ urine, when the ions at $\mathrm{m} / \mathrm{z} 158$ and 176 were used for ALMA and the internal standard (BEMA), respectively. The limit of detection of ALMA in urine was $10 \mu \mathrm{g} / 1$ for identification (signal to noise ratio $(\mathrm{S} / \mathrm{N})=3$ ) and $25 \mu \mathrm{g} / 1$ for measurement purposes $(S / N=10)$. Urinary
ALMA concentrations were corrected for differences in urine production by creatinine excretion. The urinary ALMA concentrations found were between the limit of detection (25 $\mu \mathrm{g} / \mathrm{l})$ and $3550 \mu \mathrm{g} / \mathrm{l}$.

In this report, the shutdown period in 1993 is evaluated in more detail, because full record was made on the lifestyle factors smoking and garlic consumption in 1993. During this shut down period data from 63 workers and 114 workshift periods were collected and evaluated. Table 3 shows data on potential AC exposure, ALMA excretion, and lifestyle factors from a representative part of this population. Twelve of the workers reported the consumption of garlic on a regular basis, whereas 20 and 31 workers were irregular and non-consumers of garlic. Twenty eight workers reported that they smoked. The ALMA excretion before the shift ranged from the detection limit of the assay to $2354 \mu \mathrm{g} / \mathrm{g}$ creatinine (mean (SD), median, 193 (335), 72). The ALMA excretion in samples after the shift ranged from 4 to $2111 \mu \mathrm{g} / \mathrm{g}$ creatinine (mean (SD), median 254 (351), 133). The urinary excretion of ALMA upon the consumption of garlic is evident from the first samples before the shift. The mean (SD), median (range) ALMA excretion in these samples from irregular and non-consumers of garlic was 82.5 (121), 38 (not detectable-546) and $75.4(90.0), 34(7-356) \mu \mathrm{g} / \mathrm{g}$ creatinine, respectively. Regular garlic consumers excreted significant (Wilcoxon rank sum test, $\mathrm{P}<0.05$ ) higher amounts of ALMA in the first samples before the shift: mean (SD), median (range) 411 (687), 70 (20-2354) $\mu \mathrm{g} / \mathrm{g}$ creatinine. Garlic consumption could occasionally lead to high ALMA excretion in other samples, as illustrated by the urine samples collected from workers $F$ and $\mathrm{H}$ (table 3). Smoking did not influence the urinary excretion of ALMA upon exposure to AC.

For every worker a time course for ALMA excretion in relation to airborne $A C$ was constructed. Figure 2 shows three of them. In workers $\mathrm{C}$ and $\mathrm{E}$ (fig $2 \mathrm{~A}$ and $\mathrm{B}$ ), both non-smokers and not garlic consuming, repeated exposures to airborne AC resulted in increases of the urinary ALMA excretion over the workshifts. In worker $E$, the occupational hygienist noted dermal exposure during one workshift. The additional dermal exposure resulted in a relatively high urinary excretion of ALMA compared with the air concentrations of AC. Dermal exposure was also identified in the same way, in two more cases (not shown). Worker F (fig 2C), who consumed garlic and smoked, excreted relatively high amounts of ALMA. Garlic consumption may well have contributed to the urinary ALMA excretion in this worker. However, during the first workshift no occupational exposure to AC was evident from personal air monitoring data, and consequently the ALMA excretion in urine decreased during the shift as was expected. During the second shift, however, a respiratory exposure to $\mathrm{AC}$ was measured with personal air monitoring and this resulted in an increase in urinary ALMA excretion during this shift. The relatively high ALMA excretion at the begin- 
Table 3 Inhalatory potential exposure to allyl chloride $(A C)(8 h-T W A)^{*}$, lifestyle factors and urinary excretion of $A L M A$ in some of the workers $(n=16)$ involved in the shutdown period of the AC production factory in 1993

\begin{tabular}{|c|c|c|c|c|c|c|c|}
\hline \multirow[b]{2}{*}{ Worker } & \multicolumn{2}{|c|}{ Life-style factor } & \multirow{2}{*}{$\begin{array}{l}\text { Shift } \\
n\end{array}$} & \multirow{2}{*}{$\begin{array}{l}A C m g / m^{3} \\
(8 h-T W A)\end{array}$} & \multirow{2}{*}{$\begin{array}{l}\text { Respiratory } \\
\text { protection }\end{array}$} & \multicolumn{2}{|c|}{$A L M A$ ( $\mu g / g$ creatinine $)$} \\
\hline & Garlic & Smoking & & & & Before shift & After shift \\
\hline \multirow[t]{2}{*}{ A } & $-t$ & $-\ddagger$ & 1 & 0.19 & $+\pi$ & 28 & 211 \\
\hline & & & 5 & 0.08 & - & 113 & 60 \\
\hline \multirow[t]{2}{*}{ B } & - & - & 1 & 0.26 & + & 43 & 91 \\
\hline & & & 2 & 0.0 & + & 1246 & 253 \\
\hline \multirow[t]{4}{*}{ C } & - & - & 1 & 2.90 & - & 7 & 227 \\
\hline & & & 2 & 1.60 & - & 232 & 295 \\
\hline & & & 3 & 1.80 & - & 202 & 587 \\
\hline & & & 4 & 1.40 & - & 36 & 393 \\
\hline D & - & + & 1 & 7.70 & - & 20 & 821 \\
\hline \multirow[t]{4}{*}{$\mathrm{E}$} & - & - & 1 & 0.34 & + & 13 & 72 \\
\hline & & & 2 & 1.80 & + & 59 & $1265 \|$ \\
\hline & & & 3 & 0.26 & + & 411 & 396 \\
\hline & & & 4 & 3.80 & + & 122 & 641 \\
\hline \multirow[t]{2}{*}{$\mathbf{F}$} & + & + & 1 & 0.0 & $?$ & 2354 & 1124 \\
\hline & & & 2 & 0.14 & $?$ & 598 & 818 \\
\hline G & \pm & + & 1 & 14.0 & - & 25 & 905 \\
\hline $\mathrm{H}$ & + & - & 1 & 0.0 & $?$ & 753 & 617 \\
\hline \multirow[t]{2}{*}{ I } & \pm & - & 1 & 0.0 & + & 154 & 304 \\
\hline & & & 2 & 0.15 & + & 82 & 45 \\
\hline $\mathrm{J}$ & + & - & 1 & 0.0 & + & 73 & 55 \\
\hline $\mathrm{K}$ & - & - & 1 & 4.9 & + & 51 & 45 \\
\hline \multirow[t]{2}{*}{$\mathrm{L}$} & + & + & 1 & 0.0 & - & 28 & 31 \\
\hline & & & 2 & 0.0 & - & 104 & 70 \\
\hline \multirow[t]{2}{*}{$\mathbf{M}$} & + & - & 1 & 0.31 & + & 136 & 132 \\
\hline & & & 7 & 0.0 & - & 14 & 9 \\
\hline \multirow[t]{2}{*}{$\mathbf{N}$} & - & - & 1 & 5.9 & - & 18 & 541 \\
\hline & & & 3 & 2.3 & - & 104 & 349 \\
\hline \multirow[t]{2}{*}{0} & - & - & 1 & 1.0 & - & 153 & 294 \\
\hline & & & 2 & 0.0 & - & 202 & 151 \\
\hline $\mathbf{P}$ & \pm & + & 1 & 14 & - & 28 & 686 \\
\hline
\end{tabular}

* $8 \mathrm{~h}-\mathrm{TWA}=$ eight hour time weighted average; $\uparrow$ garlic consumption $-=$ no, $\pm=$ irregular,$+=$ regular garlic consumer; $\ddagger$ smoking habits $-=$ non-smoker, $+=$ smoker; $\$ the detection limit of the method was $0.1 \mathrm{mg} \mathrm{AC} / \mathrm{m}^{3}$ air $(8 \mathrm{~h}-\mathrm{TWA})$; I respiratory protection - = without, $+=$ with, ? = unknown; $\|=$ dermal exposure was noted.

ning of the second shift of worker $B$ is enigmatic (table 3). This high excretion was found despite low exposures, and no reported garlic consumption nor potential dermal exposure, although both factors could have contributed to this result.

In 1992, two high air concentrations of AC were measured outside the respiratory protection equipment. These potential exposures did not lead to high ALMA excretion ( $<352 \mu \mathrm{g} / \mathrm{g}$ creatinine), indicating low internal doses of AC.

Figure 3 shows a correlation between the respiratory $8 \mathrm{~h}$-TWA exposures to $\mathrm{AC}$ and the values of ALMA in urine samples collected at the end of the shift minus the values before the shift of workers who did not use respiratory protection equipment. In some of the cases, the difference in ALMA excretion between values after and before the shift resulted in a negative increase, because relatively high excretion of ALMA at the beginning of the workshift was noted. Apparently garlic consumption or potential exposures during the preceding day caused this result and therefore these data were not used in the correlation. Only one data point per worker was used in the correlation. However, not all workers are involved due to missing samples or obvious other potential exposures - for example, dermal). The correlation is independent of such lifestyle factors as smoking or garlic consumption. The increases of the urinary ALMA concentrations during the shifts correlated well with the corresponding 8h-TWA air concentrations of AC ( $y=27$ $+107 \mathrm{x}, r=0.816, \mathrm{P}=0.0001, \mathrm{n}=39$ ). From
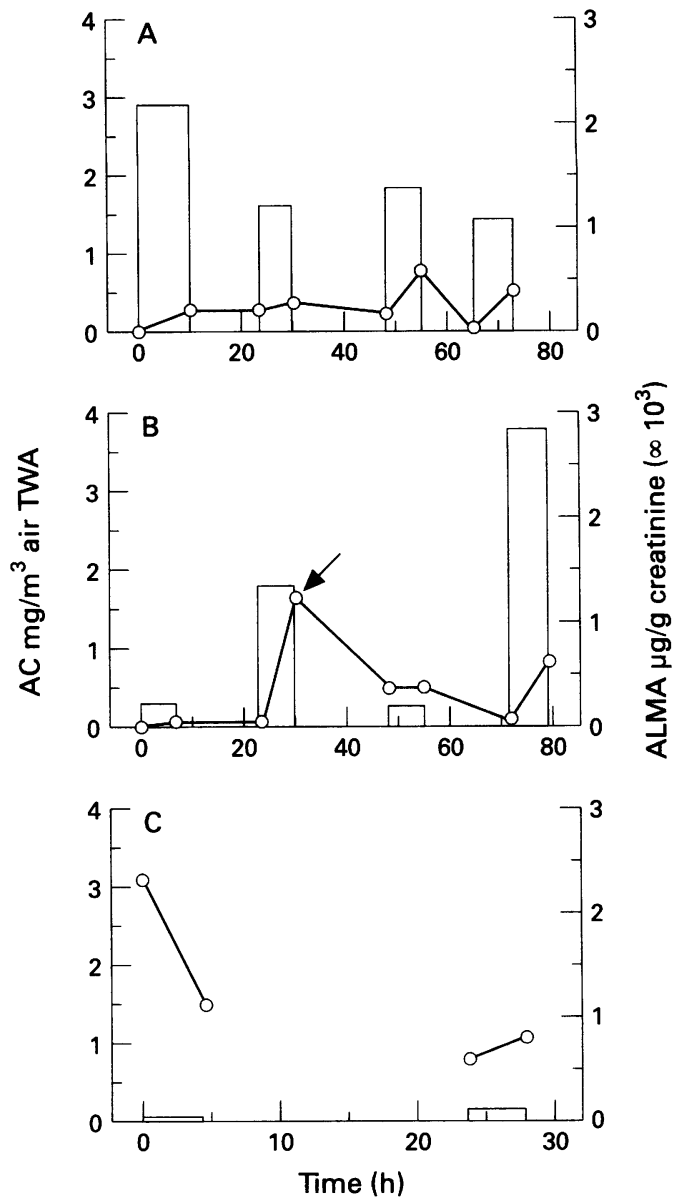

Figure 2 Time courses for urinary ALMA excretion (circles) relative to airborne AC (blocks) in three different workers during one working week. (A) Worker C: a typical example of a clear relation between the workshifts and the urinary excretion of $A L M A$. (B) Worker $E$ : during the second day that dermal exposure to AC occurred (indicated by arrow). (C) Worker F: relative high urinary

concentrations of ALMA possibly resulting from garlic consumption. Despite garlic consumption, the potential exposure to airborne AC still resulted in an increase in urinary ALMA concentrations during the second workshift.

fig 3, it is estimated that exposure to airborne concentrations of $A C$ equal to the OEL ( $1 \mathrm{ppm}$ or $3 \mathrm{mg} / \mathrm{m}^{3}$ air; $8 \mathrm{~h}$-TWA) would lead to a mean urinary ALMA excretion of $352 \mu \mathrm{g} A \mathrm{LMA} / \mathrm{g}$ creatinine. The $95 \%$ confidence intervals $(95 \%$ CIs) for the regression line give $242-462 \mu \mathrm{g}$ ALMA $/ g$ creatinine at the level of the OEL. As expected, no relation was found between air concentrations of $\mathrm{AC}$ and the increase of ALMA excretion during the workshifts when respiratory protection equipment was used.

\section{Discussion}

During three annual shut down periods in an AC production factory this biomonitoring study was undertaken in maintenance workers to elucidate whether urinary mercapturic acid excretion might be used as a biomarker of exposure to AC. During the shut down periods, the production was stopped, installations were cleaned, and maintenance was performed. Depending on the job type, workers wore different kinds of protective clothing and respiratory protective equipment. Potential exposure to AC was determined in breathing zone air by personal air monitoring with monitors for organic vapours. In most cases 


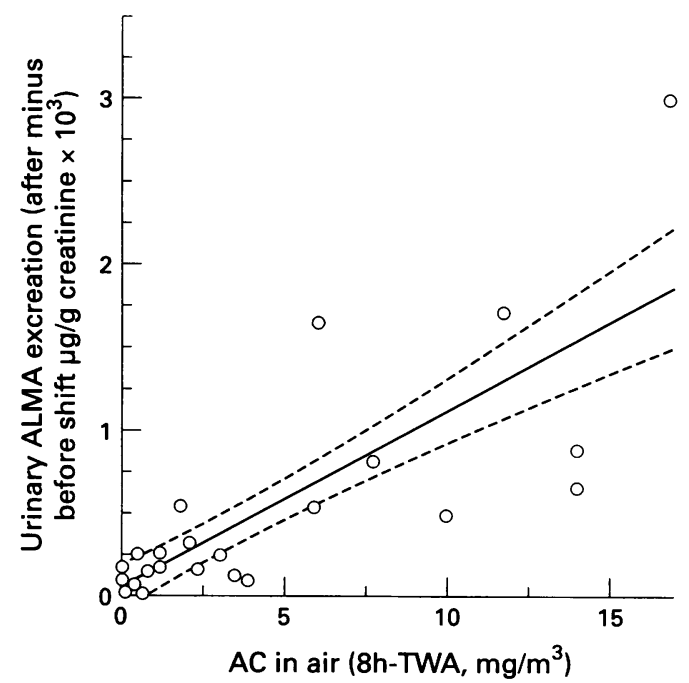

Figure 3 Correlation between $8 h-T W A$ respiratory exposure of maintenance workers to $A C$ and urinary $A L M A$ excretion (value after minus value before the shift). Only workers who did not use any respiratory protection equipment were included $(n=39)$. The $95 \%$ CIs for the regression line are shown by the dotted lines.

where no respiratory protection was applied (n $=86$ ) the potential exposure to AC was below the 8h-TWA Dutch occupational exposure limit (OEL) of $3 \mathrm{mg} \mathrm{AC} / \mathrm{m}^{3}{ }^{2}$ However, during a limited number of workshifts $(n=13)$ the potential exposure exceeded the OEL (ranging from 3.3 to $17 \mathrm{mg} \mathrm{AC} / \mathrm{m}^{3}$ ). In other production units where $A C$ is produced or used in the production of epichlorohydrin, comparable or higher air concentrations of $\mathrm{AC}$ were reported: 3-350 or $0.016-19 \mathrm{mg} \mathrm{AC} / \mathrm{m}^{3}$ or $<0.3-11.2$ mg AC/m 3 8h-TWA. $^{3}$

ALMA is a known urinary mercapturic acid metabolite of $\mathrm{AC}$ in the rat. ${ }^{14}{ }^{15}$ However, different percentages of the AC dose have been reported to be excreted in urine. In the rat, excretion percentages ranged from $1.7 \%{ }^{14}$ to $30 \%$ of the AC-dose. ${ }^{16}$ The route of administration, the dose level, the strain of rats, and analytical aspects may have contributed to these differences. The excretion of ALMA was identified by electron impact and chemical ionisation mass spectrometry, in urine samples of maintenance workers involved in shut down periods in the AC production factory in the present study. The excreted amounts of ALMA as measured with electron impact SIMGC-MS were in a range from the detection limit $(25 \mu \mathrm{g} / \mathrm{l})$ to $3550 \mu \mathrm{g} / \mathrm{l}$ urine. Corrected for creatinine excretion, the increases in the urinary excretion of ALMA found during the various work shifts correlated well with the measured potential exposure to AC ( $r=0.816$, $\mathrm{P}=0.0001, \mathrm{n}=39$; fig 3 ). In some samples the values of ALMA excretions collected at the end of the shift minus values before the shift were negative due to relatively high excretion of ALMA at the beginning of the workshifts. Apparently garlic consumption or potential exposures during the preceding day caused this result and therefore these data were not used in the correlation. As expected, no relation was found between air concentrations of $A C$ and the increase of ALMA excretion during the workshifts when respiratory protection equip- ment was used. This indicates that, in general, the protection equipment when applied was effective in preventing internal exposure to AC. With Z- and E-3-chloropropenylmercapturic acid, previously used as biomarkers of human exposure for the nematocides Z- and E-1,3dichloropropene, similar correlations were found. ${ }^{25}$ From the correlation found between the urinary ALMA excretions during the workshifts and the concomitant air concentrations of AC, it was calculated that exposure to air concentrations of $\mathrm{AC}$ at the level of the present OEL $\left(3 \mathrm{mg} / \mathrm{m}^{3}\right)^{2}$ would lead to a mean urinary ALMA excretion of $352 \mu \mathrm{g}$ ALMA $/ \mathrm{g}$ creatinine (95\% CIs: $242-462 \mu \mathrm{g}$ ALMA/g creatinine). Based on this correlation, we propose a biological exposure index (BEI) for human exposure to $\mathrm{AC}$ as an increase of $352 \mu \mathrm{g}$ ALMA/g creatinine during an eight hour workshift.

In the present study some unexpectedly high excretions of ALMA in urine were found. In some cases, it was evident that dermal exposure contributed to the higher urinary excretion of ALMA. However, in other cases of unexpectedly high excretions of ALMA in urine, no clear alternative occupational exposures to AC were found. These cases could also not be related to reported smoking habits. Most likely garlic consumption is a major course of the incidentally high ALMA excretions. The excretion of ALMA after garlic consumption was identified before ${ }^{17}$ and in a study with human volunteers, garlic consumption has been shown to lead to urinary ALMA concentrations up to $2000 \mu \mathrm{g} / \mathrm{l}$ urine. ${ }^{30}$ In the urine of several maintenance workers occupationally exposed to AC and not consuming garlic, urinary ALMA concentrations up to $3550 \mu \mathrm{g} / \mathrm{l}$ were found. Additionally, regular garlic consumers showed higher ALMA concentrations in the first samples before the shift than did irregular and non-consumers of garlic. Garlic consumption apparently has to be considered as a potential confounder for urinary ALMA excretion. However, despite this potential confounding factor the increases in ALMA concentrations during workshifts correlated well with the potential exposure of the workers to AC. The phenomenon of confounding factors has been well described for biomarkers of exposure. For instance, phenylmercapturic acid, a biomarker for occupational exposure to benzene, was also found to be excreted in a group of smokers and non-smokers not occupationally exposed to benzene. ${ }^{31}$ Nevertheless, phenylmercapturic acid was successfully used as a biomarker of occupational exposure to benzene. ${ }^{26}{ }^{27}$ Another example is $\mathrm{N}$-(2-hydroxyethyl) valine in haemoglobin. This protein adduct derived compound has been used as a biomarker of exposure to ethylene oxide and has also been detected in smokers and non-smokers not occupationally exposed to ethylene oxide. ${ }^{32} 33$

For the purpose of risk assessment of human exposure to selected chemicals, information about the internal dose is vital. ${ }^{34}{ }^{35}$ Historical records, environmental monitoring, and biological monitoring are used by occupational hygienists to assess exposures. ${ }^{35} \mathrm{With}$ historical 
records and environmental monitoring the potential exposure of workers to a certain chemical may be identified. By performing biological monitoring, however, information on a cumulative internal dose may be obtained or the effectiveness of respiratory protection may be assessed. ${ }^{36}$ Recently, several criteria for biomarkers of exposure were formulated-for example, relation with dose, sensitivity, selectivity, and relation with adverse health effects. ${ }^{34}$ In the present study, a clear relation was found between the potential exposure to $\mathrm{AC}$ and the biomarker ALMA in urine of workers. The present method of analysing ALMA in urine was sensitive enough to determine the excretion of ALMA upon exposure to AC at or below the 8h-TWA OEL. Although ALMA is apparently a good biomarker for the assessment of the internal dose of AC, the consumption of garlic is a potential confounder. Some other electrophilic chemicals, such as the other allyl halides, ${ }^{14}$ allyl nitrate, allyl sulphate, and allyl phosphate, ${ }^{13}$ may lead to the urinary excretion of ALMA as well. However, none of these chemicals were used in the AC production factory in which the use of ALMA as biomarker was evaluated. AC is often used in the production of epichlorohydrin. ${ }^{\prime}$ ALMA was not identified as a metabolite of this compound in the urine of rats treated with epichlorohydrin ${ }^{37}$ and no influence of potential exposure to epichlorohydrin could be identified on the urinary excretion of ALMA in workers exposed to AC.

By concomitant determination of more urinary metabolites of AC it would, in principle, be possible to construct a metabolite profile. Such a profile may possibly be used to assess the relative contribution of exposure to AC and of other sources of ALMA to the urinary ALMA excretion. To test this hypothesis attempts were made to determine the urinary excretion of HPMA in this study as well. The urinary excretion of $\alpha-\mathrm{CH}$ or CHPMA were not selected for this purpose, because epichlorohydrin was used in a neighbouring production factory and the urinary excretion of $\alpha-\mathrm{CH}$ and CHPMA was described in rats treated with epichlorohydrin. ${ }^{37}$ The excretion of HPMA was identified in traces in urine samples of a few workers. However, in some of these cases there was no clear previous exposure to AC. The excretion of HPMA has also been identified in rats treated with acrolein. ${ }^{13}{ }^{15}$ Acrolein is a known constituent of cigarette smoke, which has been found in the so called main stream ${ }^{18}$ and side stream smoke. ${ }^{19}$ Therefore, smoking may be a source of urinary HPMA in those cases where no exposure to AC was reported. We were not able to measure urinary HPMA concentrations accurately, due to a relatively low response and poor reproducibility of the analytical method applied.

\section{Conclusions}

The mercapturic acid ALMA was unequivocally identified in urine samples of maintenance workers with potential inhalatory exposure to AC, and the analytical method, which was based on SIM-GC-MS, was selective and sensitive enough to measure the urinary excretion of ALMA in workers exposed to ambient air concentrations of $A C$ around and below the current 8h-TWA-OEL of $3 \mathrm{mg} \mathrm{AC} / \mathrm{m}^{3}$. $^{2}$ Apart from inhalatory exposure to $\mathrm{AC}$, urinary ALMA excretion may also be used to identify dermal exposure to AC. Garlic consumption, but not smoking, is a potential confounding factor for ALMA as a biomarker of human exposure to AC. The increases in ALMA excretion in urine during workshifts correlated well with the potential exposure of workers to AC. Based on this correlation an increase of $352 \mu \mathrm{g} \mathrm{ALMA} / \mathrm{g}$ creatinine during an eight hour workshift is proposed as a biological exposure index (BEI).

We thank H van der Waal, PSJ Rocchi, GR Wiemer, Safety, Occupational Health, Hygiene and Biomedical Department, van Baar, Department of Organic Chemistry, Free University, van Baar, Department of Organic Chemistry, Free
Amsterdam, for their contributions to this study.

1 International Agency for Research on Cancer. LARC-monogr Eval Carcinog Risks Hum 36; Allyl chloride. Lyon; IARC, 1985;36:39-54.

2 Ministry of social affairs. De Nationale MAC-lijst 1995. The Hague: Ministry of social affairs, Sdu, 1995. (In Dutch.)

3 Fengsheng $H$, Sou-lin Z. Effects of allyl chloride on occupa tionally exposed subjects. Scand $₹$ Work Environ Health 1985;11(suppl 4):43-5.

4 Häusler M, Lenich $R$. Zur wirkung von allylchlorid bei chronischer gewerblicher exposition. Archiv für Toxikologie 1968;23:209-14.

5 Boogaard PJ, Rocchi PSJ, Van Sittert NJ. Effects of low concentrations of chlorinated hydrocarbons on the kidney and liver of industrial workers. $B r f$ Ind Med 1993;50:331-9.

6 Boqin L, Shuwel D, Airu Y, Yinlin X, Taibao G, Tao C Studies on the toxicity of allyl chloride. Ecotoxicol Environ Safety 1982;6:19-27

7 Torkelson TR, Wolf MA, Oyen F, Rowe VK. Vapor toxicity of allyl chloride as determined on laboratory animals. $\mathrm{Am}$ Ind Hyg Assoc $\mathcal{F}$ 1959;20:217-23.

8 Mc Coy EC, Burrows L, Rosenkranz HS. Genetic activity of allyl chloride. Mutat Res 1978;57:11-5.

9 Eder E, Neudecker T, Henschler D. Correlating of alkylating and mutagenic activities of allyl and allylic compounds: standard alkylation test vs kinetic investigation. Chem Biol Interact 1982;38:303-15.

10 Neudecker T, Henschler D. Mutagenicity of chloro-olefins in the salmonella/mammalian microsome test 1 . Allyl chloride mutagenicity re-examined. Mutat Res 1985;157:1458.

11 Van Duuren BL, Goldschmidt BM, Leowengart G, Smith AC, Melchionne S, Seidman I, Roth D. Carcinogenicity of halogenated olefinic and aliphatic hydrocarbons in mice. $f$ Natl Cancer Inst 1979;63:1433-9.

12 Theiss JC, Shimkin MB, Poirier LA. Induction of pulmonary adenomas in strain A mice by substituted organohalides. Cancer Res 1979;39:391-5.

13 Kaye CM. Biosynthesis of mercapturic acids from allyl alcohol, allyl esters and acrolein. Biochem f 1973;134:1093-101.

14 Kaye CM, Clapp JJ, Young L. The metabolic formation of mercapturic acids from allyl halides. Xenobiotica 1972;2: 129-39.

15 Sanduja R, Ansari GAS, Boor PJ. 3-Hydroxypropylmercapturic acid: a biologic marker of exposure to allylic mercapturic acid: a biologic marker of exposure to all

16 De Rooij BM, Commandeur JNM, Groot EJ, Boogaard PJ Vermeulen NPE. Biotransformation of allyl chloride in the rat, influence of inducers on the urinary metabolic profile. Drug Metab Dispos 1996;24:765-72.

17 Jandke J, Spiteller G. Unusual conjugates in biological profiles originating from consumption of onions and garlic. $f$ Chromatogr B Biomed Appl 1987;421:1-8.

18 Phillips GF, Waller RE. Yield of tar and other smoke components from UK cigarettes. Food and Chemical Toxicology 1991;29:469-74.

19 Löfroth G, Burton RM, Forehand L, Hammond KS, Seile RL, Zweidinger RB, Lewtas J. Characterization of environmental tobacco smoke. Environmental Science and Technology 1989;23:610-4.

20 Vermeulen NPE. Analyses of mercapturic acids as a tool in biotransformation, biomonitoring and toxicological studbiotransformation, biomonitoring and tox
ies. Trends Pharmacol Sci 1989;10:177-81.

21 Van Welie RTH, Van Dijck RGJM, Vermeulen NPE, Van Sittert NJ. Mercapturic acids, protein adducts and DNA Sittert NJ. Mercapturic acids, protein adducts and DNA Toxicol 1992;22:271-306.

22 Seutter-Berlage F, Van Dorp HL, Kosse HGJ, Henderson PTh. Urinary mercapturic acid excretion as a biological parameter of exposure to alkylating agents. Int Arch Occup Environ Health 1977;39:45-51. 
23 Koob M, Dekant W. Bioactivation of xenobiotics by formation of toxic glutathione conjugates. Chem Biol Interact $1991 ; 77: 107-36$

24 Commandeur JNM, Stijntjes GJ, Vermeulen NPE. Enzymes and transport systems involved in the formation and disposition of glutathione $S$-conjugates; role in bioactivation and detoxication mechanisms of xenobiotics. Pharmacol Rev 1995;47:271-330.

25 Van Welie RTH, Van Duyn P, Vermeulen NPE. Environmental and biological monitoring of non-occupational exposure to 1,3-dichloropropene. Int Arch Occup Environ Health 1991;63:169-73.

26 Van Sittert NJ, Boogaard PJ, Beulink GDJ. Application of the urinary S-phenylmercapturic acid test as a biomarker for low levels of exposure to benzene in industry. $\mathrm{Br} \mathcal{F}$ Ind Med 1993;50:460-9.

27 Boogaard PJ, Van Sittert NJ. Biological monitoring of exposure to benzene: a comparison between sure to benzene: a comparison between

28 Furniss BS, Hannaford AJ, Smith PWG, Tatchell AR, eds. Primary and secondary amines: acetyl derivatives. In Vogel's textbook of practical organic chemistry. 5th ed. Harlow, UK: Longman, 1989:1273-4.

29 Rock RC, Walker GW, Jennings DC. Chapter 11: nitrogen metabolites and renal function. Tietz NW, ed. Textbook of clinical chemistry. Philadelphia: WB Saunders, 1986:127081

30 De Rooij BM, Boogaard PJ, Rijksen DA, Commandeur
NNM, Vermeulen NPE. Urinary excretion of N-acetyl-Sallyl-L-cysteine upon garlic consumption by human volunteers. Arch Toxicol 1996;70:635-9.

31 Stommel P, Müller G, Stücker W, Verkoyen C, Schöbel S, Norpoth K. Determination of $S$-phenylmercapturic acid in the urine - an improvement in the biological monitoring of benzene exposure. Carcinogenesis 1989;10:279-82.

32 Törnqvist M, Osterman-Golkar S, Kautianen A, Jensen S, Farmer PB, Ehrenberg L. Tissue doses of ethylene oxide in cigarette smokers determined from adduct levels in hemoglobin. Carcinogenesis 1986;7:1519-21.

33 Van Sittert NJ, Beulink GDJ, Van Vliet EWN, Van Der Waal H. Monitoring occupational exposure to ethylene oxide by the determination of hemoglobin adducts. Environ Health Perspect 1993;99:217-20.

34 Stevens DK, Bull RJ, Nauman CH, Blancato JN. Decision model for biomarkers of exposure. Regul Toxicol Pharmacol 1991;14:286-96.

35 Pirkle JL, Sampson EJ, Needham LL, Patterson DG, Ashley DL. Using biological monitoring to assess human exposure to priority toxicants. Environ Health Perspect 1995; 103(suppl 3):45-8.

36 Lowry LK. Role of biomarkers of exposure in the assessment of health risks. Toxicol Lett 1995;77:31-8.

37 Gingell G, Mitschke HR, Dzidic I, Beatty PW, Sawin VL, Page AC. Disposition and metabolism of Drug oral adm

\section{Correspondence and editorials}

Occupational and Environmental Medicine welcomes correspondence relating to any of the material appearing in the journal. Results from preliminary or small scale studies may also be published in the correspondence column if this seems appropriate. Letters should be not more than 500 words in length and contain a minimum of references. Tables and figures should be kept to an absolute minimum.
Letters are accepted on the understanding that they be subject to editorial revision and shortening.

The journal also publishes editorials which are normally specially commissioned. The Editor welcomes suggestions regarding suitable topics; those wishing to submit an editorial, however, should do so only after discussion with the Editor. 